Squibb, Chugai, Daiichi-Sankyo, Eisai, Janssen, Takeda, and UCB Japan, Kenya Terabe: None declared, Naoki Ishiguro Grant/research support from: AbbVie, Asahi Kasei, Astellas, Chugai, Daiichi-Sankyo, Eisai, Kaken, Mitsubishi Tanabe, Otsuka, Pfizer, Takeda, and Zimmer Biomet, Consultant of: Ono, Speakers bureau: Astellas, Bristol-Myers Squibb, Daiichi-Sankyo, Eli Lilly, Pfizer, and Taisho Toyama DOI: 10.1136/annrheumdis-2020-eular.3541

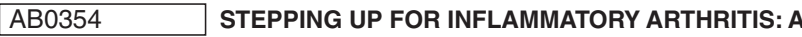 PILOT TRIAL TO TEST BEHAVIORAL ECONOMICS STRATEGY TO INCREASE PHYSICAL ACTIVITY IN INFLAMMATORY ARTHRITIS}

A. Ogdie $^{1}$, M. Patel ${ }^{1}$, J. Curtis ${ }^{2}$, K. Gavigan ${ }^{3}$, W. B. Nowell ${ }^{3}$, J. Baker ${ }^{1}$. ${ }^{1}$ University of Pennsylvania, Philadelphia, United States of America; ${ }^{2}$ University of Alabama, Birmingham, United States of America; ${ }^{3}$ Global Health Living

Foundation, New York, United States of America

Background: Regular physical activity may have benefits for patients with rheumatoid arthritis (RA) and psoriatic arthritis (PsA), but patients with active disease are often reluctant to increase activity. Principles from behavioral economics (BE), a field combining psychology and economics, have been applied to motivate increased physical activity in non-arthritis patients. ${ }^{1}$ No published studies have examined the application of BE concepts in rheumatology to promote exercise. Objectives: To assess the feasibiility and efficacy of a loss aversion financial incentive for increasing step counts and improving disease symptoms in RA and PsA patients with active disease.

Methods: A randomized controlled pilot trial was performed among patients with RA and PsA. Participants were required to have active disease defined by having at least one swollen joint and a Routine Assessment of Patient Index Data-3 (RAPID3) score $>3$ (range $0-30$ with $<3$ indicating remission). The trial included two visits (baseline and 14-week) and weekly check-ins via virtual trial platforms, Way to Health and the ArthritisPower app. Patients were given a Fitbit Alta at baseline and completed a two-week run-in period to assess average step count. Patients were then prompted to select a step count goal and complete a commitment contract. After selection of a goal, participants randomized to the intervention arm received a financial loss aversion incentive (each month, patients started with $\$ 75$ in their account and lost $\$ 2.50$ for each day they did not reach their goal). Patients were blinded to the other study arm and investigators were blinded to assignment. All patients received weekly text message prompts providing feedback about their performance over the previous week, completed weekly PROs, and had the opportunity to report adverse events including flares of joint pain. After 12 weeks of the intervention (at week 14), the incentive was removed and patients were followed to 26 weeks to determine how long the effect persisted. Results: In the pilot trial, 71 patients were verbally consented for screening, 34 underwent screening (of these, two were ineligible), 27 were randomized, and 22 patients completed the 14-week study visit. Mean age of participants was 50 (SD 13), $85 \%$ were female, $17(63 \%$ ) had PsA, mean BMI was 30.6 and mean swollen (0-66) and tender (0-68) joint counts were 6.2 (5.6) and 8.1 (9.1), respectively. Baseline RAPID3 was 10.5 (SD 4.6) and the mean step count at baseline was 5,962 . By 28 days, $65 \%$ of patients increased their step count. Participants receiving the incentive had an average of 714 more steps per day over the first 14 weeks and a greater probability of reaching 10,000 steps per day during follow-up (30\% v. $21 \%, p=0.41)$. Among patients who achieved their step count goals more than $50 \%$ of days, we observed more improvement in sleep quality, fatigue, and overall well-being $(p<0.05)$ (Figure 1). After adjusting for baseline RAPID3, the 14-week RAPID3 scores were lower in the group that achieved their step goals $50 \%$ of the time [B: $-3.91(-11.8,3.99)$; a difference that approximates the minimal clinically important difference (MCID) for the RAPID3 (3.6).

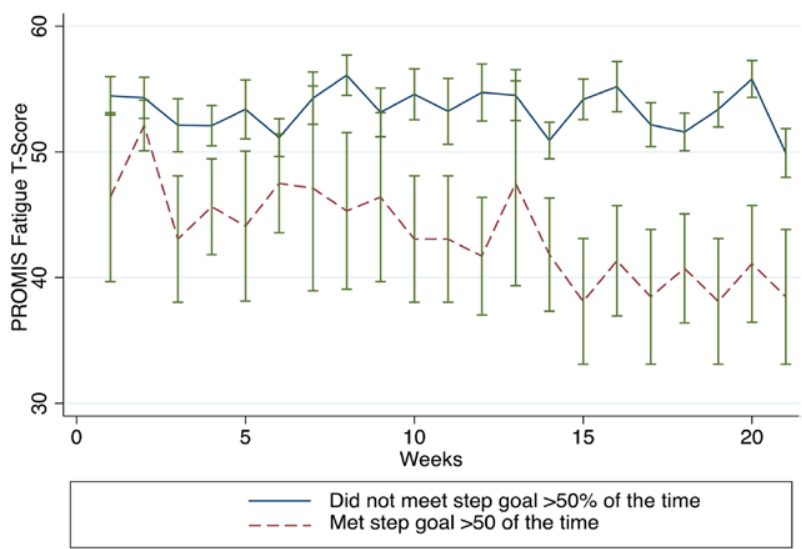

Figure 1. Change in fatigue severity among those with greater adherence to step count goals.
Conclusion: While financial incentives have worked well in patients without arthritis, the estimated effect of the financial incentive in this small study was more modest in patients with RA and PsA. Those that were able to increase their physical activity and meet their step goals had greater improvements in symptoms over the course of the study. These data support further study in this area to promote physical activity by leveraging concepts from behavioral economics.

References:

[1] Ogdie \& Asch. Nat Rev Rheumatol. 2019

Disclosure of Interests: Alexis Ogdie Grant/research support from: Pfizer, Novartis, Consultant of: Abbvie, Amgen, BMS, Celgene, Corrona, Janssen, Lilly, Pfizer, Novartis, Mitesh Patel Shareholder of: Owner, Catalyst Health LLC, Consultant of: Advisory Board Member for Healthmine Services, Life io, Holistic Industries, Jeffrey Curtis Grant/research support from: AbbVie, Amgen, Bristol-Myers Squibb, Corrona, Janssen, Lilly, Myriad, Pfizer, Regeneron, Roche, UCB, Consultant of: AbbVie, Amgen, Bristol-Myers Squibb, Cor rona, Janssen, Lilly, Myriad, Pfizer, Regeneron, Roche, UCB, Kelly Gavigan: None declared, W. Benjamin Nowell: None declared, Joshua Baker: None declared

DOI: 10.1136/annrheumdis-2020-eular.3373

\section{AB0355 EFFECT OF TOFACITINIB IN TREG /TH17 BALANCE IN RHEUMATOID ARTHRITIS}

V. A. Pacucci ${ }^{1}$, C. Barbati $^{2}$, F. R. Spinelli ${ }^{1}$, F. Ceccarelli ${ }^{1}$, S. Mancuso ${ }^{1}$,

C. Garufi ${ }^{1}$, C. Alessandri ${ }^{1}$, F. Conti ${ }^{1} .{ }^{1}$ Sapienza University of Rome, Rome, Italy; ${ }^{2}$ Sapienza University of Rome, Rome, Italy

Background: Rheumatoid arthritis (RA) is a systemic chronic autoimmune disease that can cause progressive articular destruction (1). The imbalance between Tregs and Th17-cells - an effector T-cell subset acting as Treg antagonists - is closely linked to autoimmunity (2). A shift in the Th17/ Treg balance towards the pro-inflammatory Th17 side has been reported in many autoimmune disorders including RA (4-5). Tofacitinib is the first janus kinases (JAK) inhibitor (JAKi) approved for the treatment of RA and it binds to and competitively inhibits the kinase domain of JAK3, JAK1 and, to a lesser degree, JAK2. Data on JAKi and Th17 cells/regulatory T cells (Tregs) are only available for ruxolitinib, a JAKi registered for myeloproliferative diseases (6).

Objectives: Our project aimed at investigate the possible effect of Tofacitinib on the Treg/Th17 balance in RA patients.

Methods: We isolated Peripheral Blood Mononuclear Cells (PBMCs) from patients affected by RA at baseline (TO) and after one month of Tofacitinib therapy (T1). By flow cytometry we characterized Treg and Th17 at T0 and T1. Clinical and laboratory data of the patients were collected in a standardized computerized and electronically filled form. We assessed the disease activity by using DAS-28 (CRP). Data were expressed as mean(SD) or median (interquartile range, IQR) according to the variables' distribution. Mann-Whitney and Spearman test were used. The values of $P<0.05$ were considered statistically significant.

Results: We isolated PBMCs from 9 patients with $R A(F: M=7: 2$, mean age $\pm S D$ $60 \pm 17.4$ years; mean disease duration \pm SD $20 \pm 6.6$ years, DAS-28 median at T0 4.14 IQR 1.6; at T1 3.08 IQR 1.3). The median percentage of Treg and Th17 at T0 and T1 were respectively: T0 1.85 IQR 0.98 T1 3.12 IQR 1.37; T0 1.64 IQR 1.4 T1 0.6 IQR 1.1. Treg significantly increased after tofacitinib treatment while Th17 showed a tendency in decreasing without achieving a statistical difference $(p=$ 0.003 and $p=0.8$, respectively) (figure 1 ). DAS-28 was negatively correlated with Treg number $(r=-0.76565, p=0.00021)$ and positively with Th17 numbers $(r=$ $0.5816, p=0.01135)$

Conclusion: This is the first study that investigated the role of JAKi on the Treg/ Th17 balance in RA showing and increase in Treg cells with a concurrent tendency in decrease of Th17 cell population. The restore of the Treg/Th17 balance was associated with the reduction of DAS-28 (CRP).

References:

[1] Mclnnes IB et al. Lancet 2017

[2] Fasching $P$ et al. Molecules 2017

[3] Han L et al. Front. Med. 2015

[4] Beringer A et al. Med. 2016

[5] Lippert E et al. Blood 2006 
Figure1. Modification of Treg (A) and Th17 (B) populations at baseline and after one month of Tofacitinib treatment in RA patients.
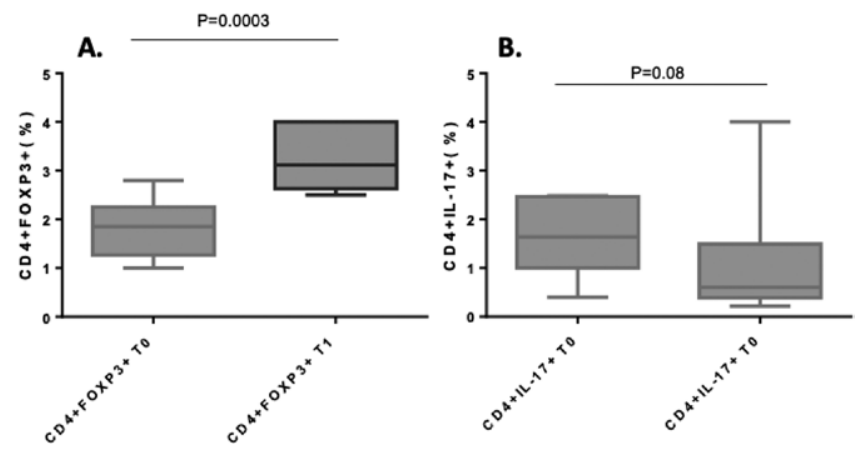

Disclosure of Interests: viviana antonella pacucci: None declared, cristiana barbati: None declared, Francesca Romana Spinelli Grant/research support from: Pfizer, Speakers bureau: Lilly, BMS, Celgene, Fulvia Ceccarelli: None declared, Silvia Mancuso: None declared, Cristina Garufi: None declared, cristiano alessandri Grant/research support from: Pfizer, fabrizio conti Speakers bureau: BMS, Lilly, Abbvie, Pfizer, Sanofi

DOI: 10.1136/annrheumdis-2020-eular.4403

\section{AB0356 TARGETING THE RHEUMATOID ARTHRITIS SYNOVIAL FIBROBLAST VIA CYCLIN DEPENDENT KINASE INHIBITION (TRAFIC): A PHASE 1B STUDY TO DETERMINE THE MAXIMUM TOLERATED DOSE OF SELICICLIB FOR REPURPOSING IN RHEUMATOID ARTHRITIS}

A. Pratt ${ }^{1}$, S. Siebert ${ }^{2}$, M. Cole ${ }^{3}$, D. Stocken ${ }^{4}$, S. Kelly ${ }^{5}$, M. Shaikh 6 , A. Cranston ${ }^{7}$, M. Morton ${ }^{7}$, J. Walker ${ }^{7}$, S. Frame ${ }^{8}$, W. F. Ng ${ }^{1}$, C. Buckley ${ }^{9}$, I. Mcinnes ${ }^{2}$, A. Filer ${ }^{9}$, J. D. Isaacs ${ }^{1} .{ }^{1}$ Newcastle University Translational and Clinical Research Institute, Newcastle upon Tyne, United Kingdom; ${ }^{2}$ Institute of Infection, Immunity and Inflammation, University of Glasgow, Glasgow, United Kingdom; ${ }^{3}$ Newcastle University Population Health Sciences Institute, Newcastle upon Tyne, United Kingdom; ${ }^{4}$ Leeds Institute of Clinical Trials Research, University of Leeds, Leeds, United Kingdom; ${ }^{5}$ Department of Rheumatology, Barts Health NHS Trust, London, United Kingdom; ${ }^{6}$ Department of Rheumatology, James Cook University Hospital, Middlesbrough, United Kingdom; ${ }^{7}$ Newcastle University Clinical Trials Unit, Newcastle upon Tyne, United Kingdom; ${ }^{8} \mathrm{Cyclacel}$ Ltd., Dundee, United Kingdom; ${ }^{9}$ Institute for Inflammation and Ageing, University of Birmingham, Birmingham, United Kingdom

Background: Current rheumatoid arthritis (RA) therapeutics target immune inflammation and are subject to ceiling effects, with non-response observed in a third of recipients together with low remission rates. Synovial fibroblasts (SFs) are stromal cells not yet targeted in RA, whose hyperplastic and proliferative properties drive inflammation and tissue destruction. Seliciclib (R-roscovitine) is an orally available cyclin-dependent kinase (CDK) inhibitor that suppresses SF proliferation and ameliorates inflammatory arthritis in rodents.

Objectives: To determine the maximum tolerated dose (MTD) of seliciclib in patients with active RA despite anti-TNF, with or without background conventional disease modifying anti-rheumatic drugs (cDMARDs). Safety and pharmacokinetics (PK) were also evaluated.

Methods: A restricted, one-stage Bayesian continual reassessment method (CRM) determined MTD based on a target dose-limiting toxicity (DLT) probability of $35 \%$. RA patients (DAS28 $\geq 3.2$ ) were recruited sequentially to cohorts of 3 subjects each. Cohort 1 received $400 \mathrm{mg}$ seliciclib daily for 4 consecutive days each week for 4 weeks, added to existing therapy. Each subsequent cohort received a dose determined by the toxicity-based CRM algorithm, calculated upon conclusion of the previous cohort. Safety was assessed through adverse event (AE) monitoring. Associations with relevant PK parameters were sought. Results: 15 anti-TNF recipients were enrolled, 10 of whom were also taking cDMARDs (median DAS28 4.9). Application of the CRM algorithm prompted one dose increment during the study (to $600 \mathrm{mg}$ for cohort 2), but reversion to $400 \mathrm{mg}$ for subsequent cohorts (Figure $1 A$ ). After treatment of 5 cohorts, $400 \mathrm{mg}$ was determined the MTD, with a DLT probability of 0.35 (Cl 0.18-0.52; Figure 1B). 6 patients experienced DLTs, of which two were classified as serious AEs (SAEs) in keeping with the safety profile of seliciclib; these are summarised in Table 1. Of $43 / 65$ total AEs reported at any dose that did not contribute to a DLT, 26 were possibly, probably or definitely related to seliciclib; 19 of these 26 were mild, 7 moderate and none severe. The most frequent $A E$ was mild nausea. No relationship of safety and/or tolerability with concomitant CDMARD use or PK was seen.

Table 1. AOutcome of contributory AEs/SAE at close of follow-up. ${ }^{\text {BSAEs }}$ classified as 'expected'. DLT: dose limiting toxicity; N+V: nausea, vomiting.

\begin{tabular}{|c|c|c|c|c|c|c|}
\hline DLT & $\begin{array}{l}\text { Seliciclib } \\
\text { dose }(m g)\end{array}$ & $\begin{array}{l}\text { Doses } \\
\text { received }\end{array}$ & $\begin{array}{c}\text { Contributing } \\
\text { AEs }\end{array}$ & $\begin{array}{l}\text { Contributing } \\
\text { SAEs }\end{array}$ & Description & Outcome $^{A}$ \\
\hline 1 & 400 & 8 & 3 & 0 & $\begin{array}{l}\text { Constipation, } \\
\mathrm{N}+\mathrm{V} \text {, liver injury; } \\
\text { fatigue. }\end{array}$ & Resolved \\
\hline 2 & 600 & 4 & 3 & 0 & $\begin{array}{c}\text { Constipation, } \\
\mathrm{N}+\mathrm{V} .\end{array}$ & Resolved \\
\hline 3 & 600 & 1 & 0 & $1^{\mathrm{B}}$ & $\begin{array}{c}\text { Fever, } \mathrm{N}+\mathrm{V} \text {, renal } \\
\text { injury. }\end{array}$ & I Resolved \\
\hline 4 & 400 & 8 & 3 & $1^{\mathrm{B}}$ & $\begin{array}{l}\text { Constipation, } \\
N+V \text {, jaundice, } \\
\text { liver injury. }\end{array}$ & Resolved \\
\hline 5 & 400 & 8 & 4 & 0 & $\begin{array}{l}\text { Fever, dizziness, } \\
\text { liver injury. }\end{array}$ & Resolved \\
\hline 6 & 400 & 8 & 9 & 0 & $\begin{array}{l}\text { Dizziness, } N+V \text {, } \\
\text { liver injury, biliru- } \\
\text { bin rise. }\end{array}$ & $\begin{array}{l}\text { Persistent } \\
\text { AST rise }\end{array}$ \\
\hline
\end{tabular}

Conclusion: The MTD of seliciclib has been defined for RA. No unexpected safety concerns were identified to preclude ongoing evaluation in patients, which focuses on clinical, radiological and biological indicators of efficacy.
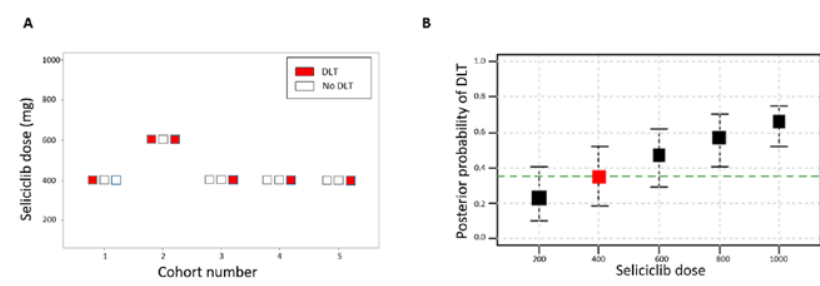

Figure 1. A. Dose limiting toxicity (DLT) occurrence by cohort and dose level (DLTs shown in red). B. Bayesian posterio probability of DLT at each dose level (with $90 \%$ confidence interval) following completion of cohort 5 . Red point indicates value closest to target of 0.35 , and hence maximum tolerated dose (MTD).

Disclosure of Interests: Arthur Pratt Grant/research support from: Pfizer, GlaxoSmithKlein, Stefan Siebert Grant/research support from: BMS, Boehringer Ingelheim, Celgene, GlaxoSmithKline, Janssen, Novartis, Pfizer, UCB, Consultant of: AbbVie, Boehringer Ingelheim, Janssen, Novartis, Pfizer, UCB, Speakers bureau: AbbVie, Celgene, Janssen, Novartis, Michael Cole: None declared, Deborah Stocken: None declared, Stephen Kelly: None declared, Muddassir Shaikh: None declared, Amy Cranston: None declared, Miranda Morton: None declared, Jennifer Walker: None declared, Sheelagh Frame Employee of: Cyclacel Ltd., Wan-fa Ng: None declared, Chris Buckley Consultant of: Janssen, Pfizer, GSK, Galapagos, Gillead, lain Mclnnes Grant/research support from: Bristol-Myers Squibb, Celgene, Eli Lilly and Company, Janssen, and UCB, Consultant of: AbbVie, Bristol-Myers Squibb, Celgene, Eli Lilly and Company, Gilead, Janssen, Novartis, Pfizer, and UCB, Andrew Filer: None declared, John D Isaacs Consultant of: AbbVie, Bristol-Myers Squibb, Eli Lilly, Gilead, Janssen, Merck, Pfizer, Roche DOI: 10.1136/annrheumdis-2020-eular.2443

\section{AB0357 USE OF TOFACITINIB AND REASONS FOR DISCONTINUATION IN CLINICAL PRACTICE}

C. Y. Soleto ${ }^{1}$, B. Serrano Benavente ${ }^{2}$, L. A. Torrens $\mathrm{Cid}^{2}{ }^{2}$, J. Martínez-Barrio ${ }^{3}$, J. Molina Collada ${ }^{2}$, J. Rivera ${ }^{2}$, T. González ${ }^{2}$, I. Monteagudo ${ }^{2}$, C. Gonzalez ${ }^{3}$, I. Castrejon ${ }^{3}$, J. M. Alvaro-Gracia ${ }^{3} .{ }^{1}$ Hospital General Universitario Gregorio Maranon, Rheumatology, Madrid, Spain; ${ }^{1}$ Hospital General Universitario Gregorio Maranon, Rheumatology, Madrid, Spain; ${ }^{3}$ Hospital General Universitario Gregorio Maranon, Madrid, Spain

Background: Tofacitinib is an oral JAK 1 and 3 inhibitor for the treatment of moderate to severe active rheumatoid arthritis (RA) or psoriatic arthritis (PsA) in adults with inadequate response or intolerant to one or more conventional disease-modifying antirheumatic drugs (cDMARDs). Since its approval by the European Medicines Agency (EMA), there is limited data about its use in daily practice in Europe.

Objectives: To describe rates and reasons for discontinuation of Tofacitinib in patients with RA and other inflammatory conditions

Methods: We identified patients with a prescription for tofacitinib at our academic center from January 2017 to January 2020. Patients were treated according to their rheumatologist evaluation following standards of care. The following variables were retrospectively collected from the electronic 